\title{
De dynamiek van sluipende crises: meekoppelen van klimaatbeleid met besluiten van vandaag
}

\author{
Vincent de Gooyert \& Heleen de Coninck*
}

\begin{abstract}
Om een sluipende crisis als klimaatverandering te adresseren is niets minder dan een systeemtransitie nodig. Een systeemtransitie is zeer complex en het slagen ervan hangt in belangrijke mate af van terugkoppelingen: mechanismen waarbij een in gang gezette beweging zichzelf versterkt of juist dempt. Alhoewel ons het zicht op sluipende crises wordt ontnomen door acute crises, is het wel degelijk mogelijk om beleid voor acute crises te koppelen aan beleid voor sluipende crises, bijvoorbeeld in beleid voor een groen herstel. In dit artikel concluderen we dat er nog onvoldoende rekening wordt gehouden met de centrale rol van terugkoppelingen en reiken we methoden aan om dit wel te doen. We geven voorbeelden van koppelingen tussen maatregelen voor de acute coronacrisis die tegelijkertijd helpen de klimaattransitie te bewerkstelligen.
\end{abstract}

\section{Het spanningsveld tussen acute en sluipende crises}

De urgentie van de klimaatcrisis leek steeds breder te worden gedeeld. Eind 2019 liepen nog tienduizenden mensen door de straten van Amsterdam om mee te doen aan de landelijke klimaatmars. Steeds meer scholieren sloten zich aan bij stakingen voor het klimaat. En toen ging de samenleving op slot. Alle aandacht ging opeens uit naar R-waarden en 'het afvlakken van de curve'. Door de coronapandemie leek het momentum van de aandacht voor het klimaat ingezakt, en de klimaattop COP26 werd met een jaar uitgesteld.

We zien ons geconfronteerd met diverse crises van verschillende aard. Sommige crises spelen op de korte termijn. Acute crises als de coronapandemie vergen vandaag aandacht en vandaag besluiten; effecten van de maatregelen (of het niet nemen ervan) zijn binnen weken zichtbaar. Andere crises zijn op het eerste gezicht minder acuut, zogenaamde sluipende crises (Boin et al., 2020). Die sluipende crises komen met het gevaar dat beleid wordt uitgesteld tot het moment dat we overvallen worden: het moment waarop de ergste gevolgen niet meer vermeden kunnen worden en het eigenlijk te laat is om effectief beleid te ontwikkelen. Waar het normaal gezien al verleidelijk is om beleid voor sluipende crises uit te stellen, maken acute crises deze valkuil nog groter. Acute en sluipende crises concurreren om aandacht en de aandacht voor meer acute crises gaat dan ten koste van oplossingen voor de sluipende.

* Dr. V. de Gooyert is universitair hoofddocent systeemdynamica aan Faculteit der Managementwetenschappen van de Radboud Universiteit. Prof. dr. H.C. de Coninck is hoogleraar socio-technische innovatie en klimaatverandering, Faculteit Technische Bedrijfskunde en Innovatiewetenschappen, TU Eindhoven en universitair hoofddocent innovatiestudies en duurzaamheid, Faculteit der Natuurwetenschappen, Wiskunde en Informatica, Radboud Universiteit. 
Het spanningsveld tussen acute en sluipende crises brengt de volgende vragen met zich mee: Hoe kunnen we beleid voor de korte en de lange termijn beter combineren? Zijn er beleidsopties voor de korte termijn die ook helpen voor langeretermijncrises? In het geval van de coronapandemie en de klimaatcrises wordt er veel gesproken over 'groen herstel' (Gusheva \& De Gooyert, 2021). Dat kan worden gezien als een poging om beleid voor de korte termijn te koppelen aan het afwenden van een langetermijncrises. Toch zien we dat hier een belangrijke kans niet wordt benut, wat voor ons de aanleiding was dit artikel te schrijven. Er is brede consensus dat het afwenden van een langetermijncrisis als de klimaatcrisis niets minder vergt dan systeemtransities: fundamentele veranderingen op allerlei verschillende terreinen (De Coninck et al., 2018). Er komt steeds meer kennis beschikbaar over de technische en sociale processen die nodig zijn om een dergelijke systeemtransitie te bewerkstelligen (Köhler et al., 2019). We zien dat bij de pogingen die nu worden ondernomen om de korte termijn met de lange termijn te koppelen (zoals met groene herstelpakketten), onvoldoende rekening gehouden wordt met de dynamiek van systeemtransities. In dit artikel introduceren we wat nodig is voor het meekoppelen van de lange termijn met de korte termijn. We denken dat effectiever beleid kan worden ontwikkeld door meer rekening te houden met de aard van sluipende crises.

Hieronder beschrijven we eerst de dynamiek van systeemtransities. Vervolgens beschrijven we hoe beleid op de korte termijn meer rekening kan houden met die dynamiek, gevolgd door een illustratie van het principe aan de hand van de casus van de coronapandemie en de klimaatcrisis, afgesloten door een discussie.

\section{De dynamiek van een systeemtransitie}

Sommige sluipende crises, zoals de klimaatcrisis, kunnen alleen adequaat het hoofd geboden worden middels systeemtransities. Een systeem is een groep van elementen waarbij de onderlinge verbindingen bepalend zijn voor het gedrag van het systeem als geheel (Meadows, 2008). Met systeemtransitie bedoelen we dat op verschillende domeinen verandering nodig is. Het beperken van en aanpassen aan klimaatverandering vergt simultaan veranderingen in bijvoorbeeld zowel de gebouwde omgeving als de zware industrie. Wat de veranderingen systemisch en transformatief maken, is dat deze verder strekken dan technologie alleen, en ingesleten structuren rondom bijvoorbeeld governance, gedrag en financiële systemen zullen moeten mee veranderen om de systeemtransitie haalbaar te maken (De Coninck et al., 2018). Hierdoor is er inherent sprake van complexiteit: er is een veelheid aan relevante elementen die op veel manieren met elkaar verbonden zijn. In het geval van de klimaatcrisis: als de zware industrie grote volumes groene waterstof gaat gebruiken, heeft dit consequenties voor de opwekking van elektriciteit, en aangezien die grotendeels duurzaam moet worden opgewekt, voor onze verhouding tot het landschap, en voor de manieren van financieren voor banken en institutionele investeerders. Als de zware industrie grote volumes biomassa gaat gebruiken, levert dit een hele andere raffinage-industrie op, en kan dit via landgebruik grote consequenties hebben voor biodiversiteit en mogelijk zelfs de voedsel- 
voorziening, wat echter sterk kan worden verlicht door veranderingen van eetpatronen richting plantaardige eiwitten, wat weer veranderingen in gedrag vereist. Door de complexiteit van de benodigde systeemtransities en brede maatschappelijke transformatie vergt een sluipende crisis een ander type besluitvorming dan een acute crisis. Bij een acute crisis ligt de nadruk op handelen dat effect heeft op de korte termijn. Voor sluipende crisis kan dat ook onderdeel zijn van het handelen, maar vaak zijn er geen eenvoudige oplossingen die zich op een korte termijn laten voltrekken, of zijn die acties onvoldoende, en consequenties en onzekerheden hebben tijd nodig om zich te vertalen in beleidsweerstand (De Gooyert et al., 2016). Bij een systeemtransitie voor een sluipende crisis zijn zo veel actoren betrokken met zulke diverse belangen, dat een harde maatregel om het ene doel dichterbij te brengen al snel resulteert in een toename van de inzet van anderen om andere doelen te behalen (Meadows, 2008). Zo ontketende in Frankrijk een accijns bedoeld om brandstofverbruik te ontmoedigen een strijd voor rechtvaardigheid (Jetten et al., 2020). Bovendien zijn er door de complexiteit zoveel onbedoelde effecten van beleid, dat deze de bedoelde effecten in omvang kunnen voorbijstreven. In de context van klimaatbeleid gaat het dan bijvoorbeeld over padafhankelijkheid, verdringing of waterbedeffecten (Gürsan \& De Gooyert, 2021; Janipour et al., 2021).

Omdat er bij sluipende crises sprake is van een lange tijdshorizon en een veelheid van onderling verbonden elementen, ontstaan er allerlei gesloten ketens van causale verbanden. Deze gesloten ketens worden ook wel terugkoppelingen genoemd (Forrester, 1961; Meadows, 2008). Een maatregel zet een beweging in gang, die weer iets anders in gang zet, et cetera. Uiteindelijk komen zulke effecten na verloop van tijd weer uit bij de oorspronkelijke elementen. Deze terugkoppelingen kennen twee varianten: versterkende terugkoppelingen en dempende terugkoppelingen. Als een in gang gezette beweging zich, via andere elementen in het systeem, uiteindelijk manifesteert in een beweging in dezelfde richting, is er sprake van een versterkend effect. Dit zijn neerwaartse of opwaartse spiralen die, als er geen andere mechanismen zijn, een escalerend, exponentieel gedrag van het systeem tot gevolg hebben. Een vicieuze cirkel is een ongewenste variant van een versterkende terugkoppeling. Als een in gang gezette beweging zich, via andere elementen in het systeem, uiteindelijk manifesteert in een beweging in de tegengestelde richting, is er sprake van een dempend effect. Dit zorgt voor inertie in een systeem, en voor het terugkomen in de oude situatie van het systeem na een verstoring of interventie van buitenaf.

Systemen bestaan uit combinaties van versterkende en dempende terugkoppelingen die samen grotendeels het gedrag van het systeem over de tijd bepalen. De structuur van het systeem (de onderlinge samenhang van de elementen in terugkoppelingen) bepaalt het gedrag van het systeem (het behalen van doelen, het al dan niet realiseren of versnellen van een transitie), en dit geheel van systeem en gedrag vatten we samen onder de noemer systeemdynamica (Forrester, 1961; Meadows, 2008). In de klimaatwetenschap kennen we dergelijke effecten in fysieke processen (bijvoorbeeld versterkende terugkoppelingen als het albedo-effect en smeltende toendra, dempende terugkoppelingen als de opname van $\mathrm{CO} 2$ in de oceaan en (in lichtere mate) het biomassa stimulerende effect van CO2). In transitiestudies worden de door terugkoppelingen gestabiliseerde systemen omschreven 
als "socio-technische regimes" die kunnen worden veranderd door destabiliserende interventies, bijvoorbeeld door nieuwe technologie of brede maatschappelijke ontwikkelingen (Geels, 2002). Het geheel van interventies, hun reactie, en hoe daar weer op te reageren wordt ook wel aangeduid als transitiemanagement (Loorbach, 2007).

De alomtegenwoordigheid van terugkoppelingen heeft belangrijke consequenties voor beleid gericht op het bewerkstelligen van systeemtransities. Er zijn sterke niet-lineaire verbanden tussen maatregelen en hun effecten. Het ingrijpen op de ene plek in het systeem kan nauwelijks tot verandering leiden, hoe groot de prikkels ook zijn, omdat een dempende terugkoppeling 'terugduwt' of omdat een ongewenst versterkend effect 'tegenwerkt'. Op de andere plek in het systeem ingrijpen kan juist tot grote effecten leiden, omdat er een gewenst versterkend effect in gang wordt gezet, of een ongewenst dempend effect wordt doorbroken. Daarom gaan we hieronder in op maatregelen voor de acute coronacrisis die tegelijkertijd gericht zijn op terugkoppelingen die klimaatverandering tegengaan.

\section{Meekoppelkansen en meekoppelrisico's}

Om adequaat beleid voor acute en sluipende crises te combineren is het van belang om rekening te houden met de systeemdynamiek van sluipende crises. Op dit moment doet besluitvorming nog niet of nauwelijks recht aan de terugkoppelingen die uiteindelijk bepalend zijn voor het wel of niet realiseren van de systeemtransities die nodig zijn om een sluipende crisis te adresseren (Mercure et al., 2020). Besluitvorming gaat nu vaak uit van een statische analyse, en gebeurt met name op basis van de directe kosten en baten, terwijl een effect dat ingrijpt op een terugkoppeling veel grotere indirecte gevolgen kan hebben dan een effect dat niet ingrijpt op een terugkoppeling. Daarom betogen we dat, om met de besluitvorming van vandaag de systeemtransities van morgen mogelijk te maken, beleidsalternatieven onderworpen moeten worden aan een dynamische analyse waarin terugkoppelingen centraal staan. Zo'n analyse bestaat uit drie onderling samenhangende vragen, zie ook figuur 1 :

- Welke terugkoppelmechanismen bepalen of een systeemtransitie versneld wordt?

- Welke beleidsalternatieven zijn er beschikbaar voor de acute crisis?

- Welke beleidsalternatieven voor de acute crisis dragen bij aan de terugkoppelmechanismen die bepalend zijn voor de langetermijnsysteemtransitie? 


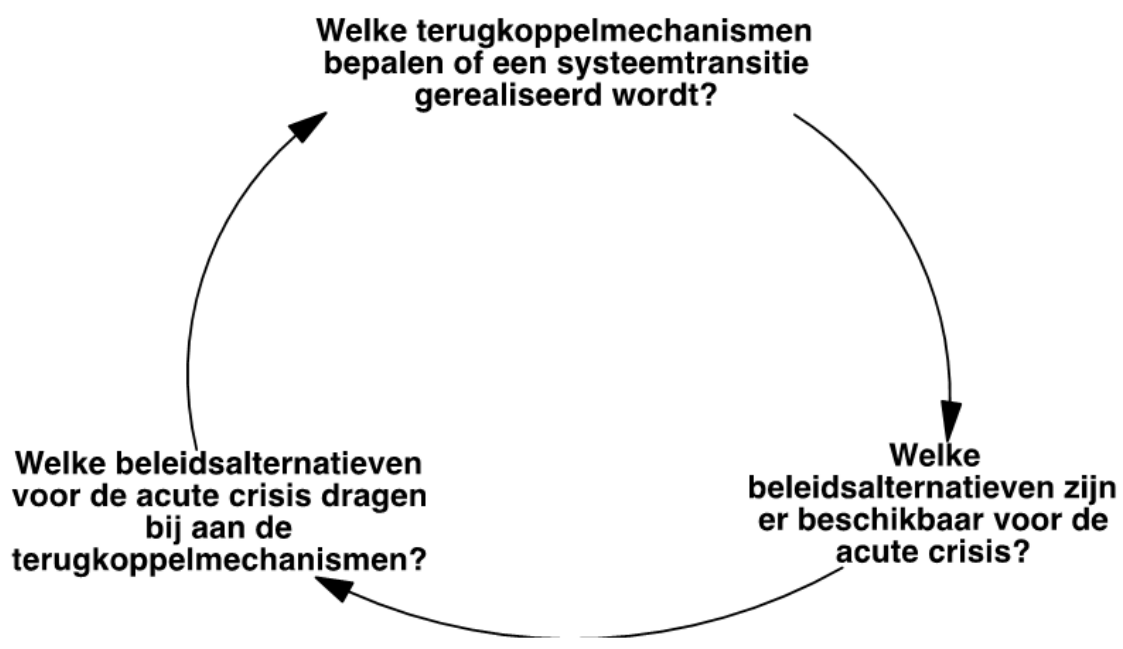

Als er beleid is voor de korte termijn dat ook helpt om terugkoppelingen voor de lange termijn te adresseren, zeggen we dat er sprake is van een 'meekoppelkans'. Andersom kunnen er ook situaties zijn waar het tegenovergestelde kan gebeuren: het kortetermijnbeleid kan terugkoppelmechanismen in gang zetten die het juist moeilijker maken om de sluipende crisis te bezweren (denk aan padafhankelijkheden); dit noemen we 'meekoppelrisico's'. Hieronder lichten we de cyclus toe aan de hand van de casus waarbij de coronapandemie de acute crisis vormt en de klimaatcrisis de sluipende crisis.

\section{Illustratie aan de hand van corona en klimaatverandering}

Hieronder lichten we deze principes toe aan de hand van de casus waarbij de coronapandemie de acute crisis vormt en de klimaatcrisis de sluipende crisis.

Welke terugkoppelmechanismen bepalen of een systeemtransitie gerealiseerd wordt? Ter illustratie, en zeker niet met de intentie om een uitputtend overzicht te geven, volgen hieronder twee terugkoppelmechanismen die regelmatig worden genoemd in de literatuur over duurzaamheidstransities: het leereffect en het zeilschipeffect (bijvoorbeeld Otto et al., 2020; Sharpe \& Lenton, 2021). Het leereffect is misschien wel een van de op dit moment meest zichtbare terugkoppelmechanismen rond de systeemtransitie die nodig zijn om de klimaatcrisis af te wenden: zonnepanelen en windenergie zijn de afgelopen jaren veel sneller goedkoper geworden dan daarvoor algemeen werd aangenomen (Creutzig et al., 2017). Het is bijna een wetmatigheid dat bij elke verdubbeling van ervaring met een bepaalde technologie de kosten van die technologie met een vast percentage afnemen (zie bijvoorbeeld Yelle, 1979). We zien hier een zichzelf versterkende terugkoppeling: hoe hoger de investeringen in 
een technologie, hoe meer ervaring er met die technologie wordt opgedaan, hoe meer er geleerd wordt over die technologie, hoe lager de kosten van die technologie, hoe aantrekkelijker het is om in die technologie te investeren, en des te hoger de investeringen in die technologie. Een voorbeeld van het zeilschipeffect (Geels, 2002) zijn de activiteiten die gevestigde partijen ondernemen om hun belangen te verdedigen. Hoe hoger de investeringen in duurzame alternatieven, des te meer activiteiten organisaties met belangen in fossiele technologie ondernemen om hun belangen te beschermen, des te aantrekkelijker het wordt om te investeren in fossiele technologie, en des te lager de investeringen in duurzame alternatieven. Voorbeelden hiervan zijn politieke druk en lobby (De Gooyert et al., 2016; Meng \& Rode, 2019; Rickards et al., 2014), maar ook het concurrerender maken van fossiele technologie door innovaties (Geels, 2002). Zie voor visuele representaties van deze twee terugkoppelingen figuur 2.

\section{Figuur 2 Voorbeelden van versterkende en dempende terugkoppelingen}
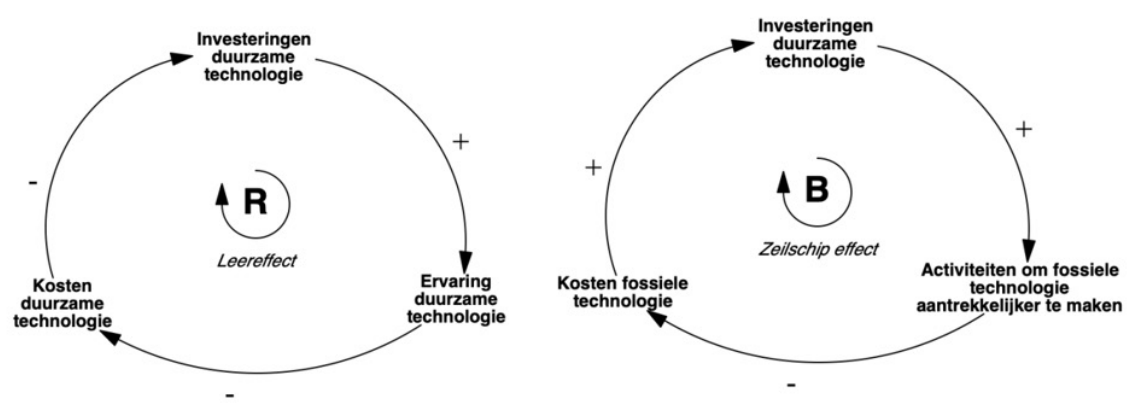

Leeswijzer: R staat voor 'reinforcing' en duidt op een versterkend effect. B staat voor 'balancing' en duidt op een dempend effect. Een pijl met een plus duidt op een positief causaal verband waarbij variabelen in gelijke richtingen bewegen, bijvoorbeeld als de investeringen in duurzame technologie toenemen (afnemen), neemt de ervaring met duurzame technologie ook toe (af). Een pijl met een min duidt op een negatief causaal verband waarbij variabelen in tegengestelde richtingen bewegen, bijvoorbeeld als de ervaring met duurzame technologie toeneemt (afneemt), nemen de kosten van duurzame technologie af (toe).

Andere terugkoppelingen doen zich bijvoorbeeld voor op het gebied van financiële markten en wetgeving (bijvoorbeeld de 'koolstofzeepbel' en het vluchten naar de uitgang wanneer het vertrouwen in 'bruine assets' inzakt, Mercure et al., 2018) en levensstijl, gedragsverandering, normen en waarden (sociale besmetting, bijvoorbeeld Gössling et al., 2020).

Welke beleidsalternatieven zijn er beschikbaar voor de acute crisis?

Het IMF (2021) geeft een analyse van het beleid van landen in reactie op de coronapandemie. Er zijn verschillende manieren om dergelijk beleid te classificeren. Een eerste onderscheid is tussen het beleid gericht op gezondheid (lock-downs, testfaciliteiten, et cetera) en het beleid gericht op de economie en de samenleving als geheel, maar voor onze analyse laten we het beleid gericht op gezondheid buiten beschouwing. Dan is er het onderscheid tussen 'relief' en 'recovery', enerzijds de 
noodpakketten om de samenleving in stand te houden door op korte termijn de zwaarste klappen helpen op te vangen, en anderzijds de meer langetermijninvesteringen die de economie en de samenleving een extra duw in de rug geven op het moment dat dat het hardst nodig is. Nederland heeft onder andere gekozen voor fiscaal beleid om de economische impact van de coronacrisis tegen te gaan, waaronder compensatie, tegemoetkoming, uitstel belastingbetalingen, garanties op leningen, belastingvoordeel en platforms om arbeidsmobiliteit te ondersteunen (IMF, 2021). De ECB en De Nederlandse Bank implementeren monetair beleid, waaronder opkoopprogramma's en het loslaten van buffereisen (IMF, 2021).

Welke beleidsalternatieven voor de acute crisis dragen bij aan de terugkoppelmechanismen dit bepalend zijn voor de langetermijnsysteemtransitie?

Als we kijken hoe het coronabeleid 'scoort' op de terugkoppelingen die relevant zijn in de context van de benodigde systeemtransitie om de klimaatcrisis af te wenden, dan vallen enkele zaken op. Generieke, niet-conditionele steunmaatregelen zoals generieke opkoopprogramma's vormen een krachtig dempend effect op de benodigde systeemtransitie doordat ze de 'oude economie' in stand houden, terwijl de transitie juist baat zou hebben bij het uitfaseren en vervangen van oude processen door nieuwe processen. Juist de organisaties die relatief veel broeikasgassen uitstoten, hebben de meeste baat bij deze generieke maatregelen (Cojoianu et al., 2020). Het vervangen van generieke door specifieke maatregelen zou helpen om beleid voor de korte termijn te koppelen aan de klimaatcrisis door een belangrijke dempende terugkoppeling van de systeemtransitie te doorbreken.

Een voorbeeld van zo'n specifieke maatregel is het maken van een onderscheid tussen groene en bruine investeringen. Als de financieringskosten van bruine investeringen toenemen, is de verwachting dat dit een versterkende terugkoppeling in gang zet, waarbij het steeds onaantrekkelijker wordt om te investeren in fossiele projecten: groene investeringen worden relatief aantrekkelijker, waardoor er meer groene investeringen worden gedaan, er meer groene leereffecten optreden en groene investeringen nog aantrekkelijker worden (Sharpe \& Lenton, 2021).

Een andere meekoppelkans is het vergroten van arbeidsmobiliteit door middel van de platforms om arbeidsmobiliteit te ondersteunen. Zonder een dergelijke maatregel, en opleiding, vormt een gebrek aan 'groengeschoolde' werknemers een dempend mechanisme op de schaalvergroting van duurzame oplossingen als besparingstechnologie, zonnepanelen en windmolens.

Een meekoppelrisico dat ons opvalt, is dat de huidige maatregelen de bestaande ongelijkheid in de samenleving hebben versterkt (CPB, 2021). Dit is een verontrustende ontwikkeling omdat juist gelijkheid een bijdrage kan leveren aan de gezamenlijkheid in de systeemtransitie. Zo konden we in Frankijk zien dat de introductie van duurzaamheidsbeleid (een verhoging van de accijns op brandstof) tot grote weerstand leidde omdat het beleid als oneerlijk werd ervaren, omdat het bestaande ongelijkheid vergroot. Ongelijkheid vormt zo een dempende terugkoppeling die terugduwt tegen beleid dat ingezet wordt om de transitie te stimuleren (Jetten et al., 2020). Als beleid voor de acute crisis leidt tot meer ongelijkheid, is dat dus precies het tegenovergestelde van het meekoppelen van de acute en de sluipende crisis; het maakt het adequaat bestrijden van de klimaatcrisis juist nog moeilijker. 


\section{Beleid dient meer recht te doen aan de dynamiek van sluipende crises}

In dit artikel betogen we dat de huidige beleidsvorming voor acute crises niet voldoende rekening houdt met de dynamiek van sluipende crises omdat geen recht wordt gedaan aan de complexiteit van de systeemtransities die nodig zijn om sluipende crises af te wenden. De huidige besluitvorming is te statisch: (maatschappelijke) kosten en baten worden afgewogen maar daarbij wordt niet ver genoeg doorgeredeneerd welke andere effecten deze kosten en baten weer tot gevolg hebben. Als je dat wel meeneemt, begin je te zien dat er terugkoppelingen actief zijn die cruciaal zijn voor het wel of niet behalen van benodigde systeemtransities. In dit artikel hebben we de gepresenteerde algemene principes geïllustreerd aan de hand van het spanningsveld tussen de acute coronacrisis en de sluipende klimaatcrisis, maar het meekoppelen van acute en sluipende crises kan ook op andere crises worden toegepast.

Het belang van terugkoppelmechanismen in socio-technische systemen is al decennia bekend (Forrester, 1961; Meadows, 2008) en hetzelfde geldt voor hun belang in transities (Geels, 2002; Köhler et al., 2019; Loorbach, 2007). Onze ideeën zijn dan ook in lijn met recente publicaties van Markard en Rosenbloom (2020), Mercure et al. (2020) en Sharpe en Lenton (2021). Toch zien we de vertaalslag naar beleidsvorming op de korte termijn nog onvoldoende in beleid terugkomen. We zien dat, ondanks de vele discussies over groen herstel, veel steunmaatregelen niet aan de criteria voor groene maatregelen voldoen (Cojoianu et al., 2020). Bovendien maken we in dit artikel een specifieker onderscheid dan maatregelen die wel of niet aan een groen herstel bijdragen. We hebben laten zien dat binnen de categorie maatregelen die bijdragen aan een groen herstel, een onderscheid te maken is tussen maatregelen die ingrijpen op terugkoppelmechanismen, en maatregelen die dat niet doen. De literatuur over complexe systemen en transities leert ons dat de maatregelen die wel terechtkomen in terugkoppelmechanismen, belangrijker kunnen zijn, omdat juist rond de terugkoppelmechanismen hefboomeffecten te verwachten zijn waar kleine investeringen grote gevolgen hebben (bijvoorbeeld Meadows, 2008).

Het toepassen van systeemdynamica ontwikkelt zich voortdurend, wat een aantal nuanceringen van onze analyse impliceert. De geopperde dynamische analyse vergt een iteratief proces waarbij telkens opnieuw wordt onderzocht welke terugkoppelmechanismen een rol spelen in benodigde transities. Welke terugkoppelingen een cruciale rol spelen in de systeemtransitie die nodig is voor de klimaatcrisis, is een voortdurende onderzoeksagenda (bijvoorbeeld Otto et al., 2020). Het is noodzakelijk om de laatste inzichten over terugkoppelingen te gebruiken om hier beleid aan te toetsen; om te leren van de 'experimenten'. Dit is bewerkelijk en daarmee kostbaar, en dergelijke additionele ex-ante toetsing zou expliciet moeten worden opgenomen in de politieke besluitvorming.

Daarnaast brengen sluipende crises met zich mee dat samenlevingen zich op punten kunnen gaan bevinden waar ze zich tot dan toe nooit bevonden hebben. De precieze dynamiek is daarom inherent onkenbaar. We zullen nooit een volledig beeld van de relevante dynamiek hebben, effecten zijn niet van tevoren zichtbaar, het is niet mogelijk om kennis te genereren middels bijvoorbeeld gecontroleerde 
experimenten, en toerekenbaarheid van effecten aan een maatregel is onzeker, terwijl dat vaak een eis is bij een ex-ante evaluatie van beleid. Het meekoppelen van acute en sluipende crises vergt daarom ook een verandering beleidsvormings- en -evaluatieprocessen.

\section{Literatuur}

Boin, A., Ekengren, M., \& Rhinard, M. (2020). Hiding in plain sight: Conceptualizing the creeping crisis. Risk, Hazards \& Crisis in Public Policy, 11(2), 116-138. https://doi. org/10.1002/rhc3.12193

Cojoianu, T. F., Collins, E., Hoepner, A. G., Magill, D., O’Neill, T., \& Schneider, F. I. (2020). In the name of COVID-19: Is the ECB fuelling the climate crisis? Environmental and Resource Economics, 1-7. https://doi.org/10.1007/s10640-020-00450-z

Coninck, H. de, Revi, A., Babiker, M., Bertoldi, P., Buckeridge, M., Cartwright, A., ... \& Sugiyama, T. (2018). Strengthening and implementing the global response. In V. MassonDelmotte, P. Zhai, H.-O. Pörtner, D. Roberts, J. Skea, P.R. Shukla., ... \& T. Waterfield (Eds.), Global warming of $1.5^{\circ} \mathrm{C}$ : An IPCC Special Report on the impacts of global warming of $1.5^{\circ} \mathrm{C}$ above pre-industrial levels and related global greenhouse gas emission pathways, in the context of strengthening the global response to the threat of climate change, sustainable development, and efforts to eradicate poverty. In press.

CPB. (2021). Macro Economische Verkenning 2021. Den Haag.

Creutzig, F., Agoston, P., Goldschmidt, J. C., Luderer, G., Nemet, G., \& Pietzcker, R. C. (2017). The underestimated potential of solar energy to mitigate climate change. Nature Energy, 2(9), 1-9. https://doi.org/10.1038/nenergy.2017.140

Forrester, J. W. (1961). Industrial dynamics. Cambridge, MT: MIT Press.

Geels, F. W. (2002). Technological transitions as evolutionary reconfiguration processes: A multi-level perspective and a case-study. Research Policy, 31(8-9), 1257-1274. https:// doi.org/10.1016/S0048-7333(02)00062-8

Gooyert, V. de, Rouwette, E., Kranenburg, H. van, Freeman, E., \& Breen, H. van. (2016). Sustainability transition dynamics: Towards overcoming policy resistance. Technological Forecasting and Social Change, 111, 135-145. https://doi.org/10.1016/j. techfore.2016.06.019

Gössling, S., Humpe, A., \& Bausch, T. (2020). Does 'flight shame' affect social norms? Changing perspectives on the desirability of air travel in Germany. Journal of Cleaner Production, 266, 122015. https://doi.org/10.1016/j.jclepro.2020.122015

Gürsan, C., \& Gooyert, V. de. (2021). The systemic impact of a transition fuel: Does natural gas help or hinder the energy transition? Renewable and Sustainable Energy Reviews, 110552. https://doi.org/10.1016/j.rser.2020.110552

Gusheva, E., \& Gooyert, V. de. (2021). Can we have our cake and eat it? A review of the debate on green recovery from the COVID-19 crisis. Sustainability, 13(2), 874. https://doi. org $/ 10.3390 /$ su13020874

IMF. (2021). Policy responses to COVID-19, The Netherlands. Https://www.imf.org/en/ Topics/imf-and-covid19/Policy-Responses-to-COVID-19\#N, bezocht op 9 juni 2021.

Janipour, Z., Swennenhuis, F., Gooyert, V. de, \& Coninck, H. de. (2021). Understanding contrasting narratives on carbon dioxide capture and storage for Dutch industry using system dynamics. International Journal of Greenhouse Gas Control, 105, 103235. https:// doi.org/10.1016/j.ijggc.2020.103235

Jetten, J., Mols, F., \& Selvanathan, H. P. (2020). How economic inequality fuels the rise and persistence of the Yellow Vest movement. International Review of Social Psychology, 33(1). http://doi.org/10.5334/irsp.356 
Köhler, J., Geels, F. W., Kern, F., Markard, J., Onsongo, E., Wieczorek, A., ... \& Wells, P. (2019). An agenda for sustainability transitions research: State of the art and future directions. Environmental Innovation and Societal Transitions, 31, 1-32. https://doi. org/10.1016/j.eist.2019.01.004

Loorbach, D. (2007). Transition management: New mode of governance for sustainable development. Utrecht: International Books.

Markard, J., \& Rosenbloom, D. (2020). A tale of two crises: COVID-19 and climate. Sustainability: Science, Practice and Policy, 16(1), 53-60. https://doi.org/10.1080/15487733.202 0.1765679

Meadows, D. H. (2008). Thinking in systems: A primer. Chelsea green publishing.

Meng, K. C., \& Rode, A. (2019). The social cost of lobbying over climate policy. Nature Climate Change, 9(6), 472-476. https://doi.org/10.1038/s41558-019-0489-6

Mercure, J. F., Pollitt, H., Viñuales, J. E., Edwards, N. R., Holden, P. B., Chewpreecha, U., ... \& Knobloch, F. (2018). Macroeconomic impact of stranded fossil fuel assets. Nature Climate Change, 8(7), 588-593. https://doi.org/10.1038/s41558-018-0182-1

Mercure, J. F., Sharpe, S., Vinuales, J., Ives, M., Grubb, M., Pollitt, H., ... \& Nijsse, F. (2020). Risk-opportunity analysis for transformative policy design and appraisal. C-EENRG Working Papers, 2020-4. pp. 1-40. Cambridge Centre for Environment, Energy and Natural Resource Governance, University of Cambridge. https://www.ceenrg.landecon.cam. ac.uk/system/files/documents/wp25.pdf

Otto, I. M., Donges, J. F., Cremades, R., Bhowmik, A., Hewitt, R. J., Lucht, W., ... \& Schellnhuber, H. J. (2020). Social tipping dynamics for stabilizing earth's climate by 2050. Proceedings of the National Academy of Sciences, 117(5), 2354-2365. https://doi. org/10.1073/pnas.1900577117

Rickards, L., Wiseman, J., \& Kashima, Y. (2014). Barriers to effective climate change mitigation: The case of senior government and business decision makers. Wiley Interdisciplinary Reviews: Climate Change, 5(6), 753-773. https://doi.org/10.1002/wcc.305

Sharpe, S., \& Lenton, T. M. (2021). Upward-scaling tipping cascades to meet climate goals: Plausible grounds for hope. Climate Policy, 21(4), 1-13. https://doi.org/10.1080/14693 062.2020.1870097

Yelle, L. E. (1979). The learning curve: Historical review and comprehensive survey. Decision Sciences, 10(2), 302-328. https://doi.org/10.1111/j.1540-5915.1979.tb00026.x 